\title{
Herejía, confesión e inquisición en el gobierno eclesiástico medieval. La dimensión política del juicio pastoral
}

\author{
Heresy, confession and inquisition in the medieval ecclesiastical \\ government. The political dimension of the pastoral judgment
}

CRISTINA CATALINA*

\begin{abstract}
Resumen: El artículo pretende evidenciar la dimensión política -en un sentido amplio- de la confesión y la inquisición en su emergencia como procedimientos para sentenciar el pecado oculto. Lo hace al insertar ambos en las formas duales, pastorales y jurídicas, que desarrolla el gobierno eclesiástico plenomedieval para la condena de la inobediencia a la nueva ortodoxia y ortopraxis romana. A este respecto, los dispositivos confesional e inquisitorial se comprenden en relación con la emergencia de lo herético como impugnación obstinada al gobierno romano -en la tensión entre el gobierno de sí y de los otros-.

Palabras clave: cristianismo medieval, herejía, inquisición, confesión, Foucault, poder pastoral.
\end{abstract}

\begin{abstract}
This article aims to underline the political dimension -in a broad sense- of the confessional and inquisitional procedures during its emergence to sentence the secret sin. To do so, both techniques are related to the dual forms, pastoral and juridical, developed by the ecclesiastical medieval government to condemn the disobedience to the new orthodoxy and orthopraxis. In this sense, confession and inquisition are understood in relation to the emergence of heresy as a stubborn contest to the Roman government -within the tension between the government of Self and Others-.
\end{abstract}

Key words: medieval Christianity, heresy, inquisition, confession, Foucault, pastoral power.

\section{De la reforma a la herejía. Ortopraxis romana y desacato ${ }^{1}$}

En el periodo en que se alzaban majestuosas catedrales -costeadas con el nuevo impuesto periódico- y se consolidaba la administración parroquial, el laicado, cuya conducta se con-

Recibido: 31/12/2017. Aceptado: 05/01/2018.

* Doctora en Filosofía y profesora asociada en el Departamento de Filosofía y Sociedad de la Universidad Complutense de Madrid. Correo electrónico: ccatalinag@gmail.com. Líneas de investigación: el papel del cristianismo en la genealogía de la cultura e instituciones políticas occidentales, la dualidad jurídica y pastoral del cristianismo medieval, la secularización fracasada y la dimensión religiosa del capitalismo moderno; filosofía política, teoría e historia social, sociología política. "Publicaciones recientes: Catalina, C., "Persistencias de la conducta pastoral: cristianismo, gubernamentalidad y capitalismo", Dorsal. Revista de Estudios Foucaultianos, número 5, 2018; Catalina, C., "Literary Expressions of Pastoral Reform during the Reign of Fernando II", en E.L. Holt; T. Witcombe (eds.) The Sword and the Cross, Leiden/Boston, Brill; 2019.

1 Este artículo ha sido posible gracias a una ayuda predoctoral FPI concedida por el Ministerio de Economía e Innovación (BES-2011-048664) dentro del proyecto de investigación Los espacios del Poder Regio, ca. 10501385. Procesos políticos y representaciones (HAR2010-21725-C03-03). 
fundía con la clerical, quedaba excluido de la administración sacramental ${ }^{2}$. En este marco, las expectativas de una religiosidad más profunda que habían alentado el apoyo popular a la reforma eclesiástica en el siglo precedente se veían incesantemente frustradas ${ }^{3}$. Los anhelos de una experiencia religiosa más pura, ofrecida por la mediación de un clero casto como aval de salvación, no siempre encontraban un cauce en las nuevas formas de cura de almas que instituía el gobierno romano ${ }^{4}$. Más bien, el aumento del poder temporal de la Iglesia, su centralización burocratizadora y la juridización de la pastoral contribuyeron al deterioro de la legitimidad carismática del sacerdocio -ya institucionalizado por rutinización-. Surgían entonces movimientos de pobreza evangélica y expresiones diversas de anticlericalismo que cuestionaban la efectividad de la gracia sacramental administrada por un clero impuro en una Iglesia opulenta ${ }^{5}$. Un fenómeno que se dio con particular intensidad en el sureste de Francia, el oeste de Alemania o el norte de Italia ${ }^{6}$, donde la proliferación en el siglo XII de líderes carismáticos comunitarios -que alentaban el desacato del clero ordenado y cuestionaban la eficacia de los sacramentos canónicos- se traduciría más tarde en contra-economías de salvación o amplios movimientos heréticos comunitarios.

Las propias expectativas evangélicas que alentaron la crítica eclesiástica fueron paradójicamente efecto del intento de cristianización que organizó la llamada reforma gregoriana? El papado de Gregorio VII había movilizado al laicado en su estrategia reformista alentándolo a la reprobación y denuncia del clero indisciplinado. Los propios cánones conciliares incitaban al laicado al boicot de los cultos ofrecidos por clérigos impuros y al vilipendio público de los obispos que incumpliesen los preceptos canónicos ${ }^{8}$. De este modo, el gobierno romano se apoyaba en la cercanía del vínculo local entre el clero y el laicado para forzar a la obediencia a su propia jerarquía ${ }^{9}$. De forma no prevista, esta movilización popular contribuiría ulteriormente a la conformación de un espacio de "opinión pública" en el marco de la justicia eclesiástica que, erigido en torno a las categorías medievales del rumor -o fama- y el escándalo -scandalum-, contribuyó a la emergencia de nuevos procedimientos sacramentales y judiciales dirigidos a la persecución de la desobediencia.

Desde este punto de vista, el relativo éxito reformista devino una trampa para los movimientos de pobreza evangélica que, si bien habían emergido al calor de la reforma, fueron pronto tachados de heréticos por un gobierno romano reforzado ahora jurídicamente ${ }^{10}$. El

2 García y García, A. (ed.) Constitutiones Concilii quarti Lateranensis Lateranensis una cum Commentariis Glossatorum. Monumenta iuris canonici(ed.), Series A: Corpus Glossatorum, vol. 2, Città del Vaticano, Biblioteca apostolica vaticana, c.1, 1981, pp. 53-54.

3 Lobrichon, G., La religion des laïs en Occident: XIe-XVe siècles, Paris, Hachette, 1994, p. 76.

4 Moore, I. R., La primera revolución europea: c.970-1215, Crítica, Barcelona, 2003, pp. 31-33 y p. 125.

5 Thery, J., "Les hérésies, du XIIe au début du XIV siècle", en Marie-Madeleine de Cevins; Jean Michel Matz (eds.), Structures et dynamiques de la vie religieuse en Occident (1179-1449), Presses Universitaires de Rennes, 2010, pp. 373-386, aquí p. 374.

6 Thery, J., "Innocent III, le rêve de la théocratie" en Les collections de L'Histoire, 26, pp. 58-61, 2006, p. 59.

7 Lobrichon, G., La religion des lä̈cs en Occident, op. cit., p. 95.

8 El canon primero del IV Concilio de Letrán instituye que el poder sacramental del sacerdote reside únicamente en el oficio clerical por delegación pontificia mediante el sacramento de la ordenación. Gaudemet, J., Église et cité: histoire du droit canonique, París, Cerf-Montchrestien, 1994, p. 482.

9 Moore, I. R., La primera revolución europea, op. cit., p. 33.

10 Lambert, M., Medieval Heresy: Popular movements form the Gregorian Reform to the Reformation, Blackwell, Oxford and Malden, 2002, p. 39. El caso del movimiento patarino es ilustrativo, habiendo disfrutado del apoyo 
reclamo de un clero de costumbres castas favoreció la diferenciación del clero y del laicado quedando éste último excluido definitivamente de la administración sacramental romana ${ }^{11}$. Al mismo tiempo, la progresiva burocratización y juridización del gobierno pastoral eclesiástico avivaba un cuasi-dualismo espontáneo y latente en las tendencias evangelistas y anticlericales, reactivando la tensión cristiana entre institución y apocalipsis o dominación legal y carismática ${ }^{12}$. La idea de la juridización del pastorado traduce analíticamente el proceso de institución por derecho de una ortopraxis y una ortodoxia a cuya participación quedaba sometido el laicado -como única vía de salvación-. Un proceso, el de normalización de la cura de almas, que supuso la erradicación de la diversidad de prácticas comunitarias de mediación espiritual y de creencias extendidas por la Cristiandad latina ${ }^{13}$. Así, en los siglos XII y XIII el núcleo del problema herético no residía en la disputa teológica, sino en la praxis religiosa discorde con la instituida por Roma. La herejía se constituyía en la dinámica de confrontación con las nuevas formas de ortodoxia y la ortopraxis romana. En esta misma dinámica emergían los inusitados dispositivos pastorales y judiciales, tales como la confesión penitencial y la inquisición ${ }^{14}$.

Mientras que Roma figuraba la propagación de lo diabólico como causa del mal y obstáculo de salvación, se presentaba como poder protector en un doble sentido, benefactor y combatiente $^{15}$. Por una parte, la Iglesia aumentaba la oferta de servicios de cura de almas como paliativos del desasosiego por la salvación a través de ritos expiatorios o modelos de conducta virtuosa. Y, por otra parte, perseguía los comportamientos que consideraba contra natura, contra la fe o contra la Iglesia. La figura del Diablo resurgía así asociada a los obstáculos de salvación, identificados con la herejía, con líderes carismáticos, con rituales religiosos o con comportamientos sexuales como la sodomía y la homosexualidad ${ }^{16}$. Si la seducción diabólica señalaba discursivamente la existencia disimulada de una iglesia del diablo, en la práctica era identificada por el gobierno eclesiástico en las expresiones de desobediencia a la ortopraxis romana ${ }^{17}$. Las fuentes eclesiásticas anunciaban que la iglesia del diablo habitaba disimulada en el interior mismo de la Cristiandad como una plaga

de Gregorio VII -quien llegó incluso a hacer mártir a su líder-, terminó por ser acusado de herético en el siglo XIII. Cfr. Violante, C., La pataria milanesa e la reforma ecclesiastica, Roma, Instituto storico italiano per il Medio Evo, 1955

11 Moore, I. R., La primera revolución europea, op. cit. p. 159.

12 Weber, M., Sociología de la religión, Buenos aires, La pléyade, 1978, p. 30.

13 Lobrichon, G., La religion des laïcs en, op. cit., p. 97-98.

14 Una estrategia caracterizada como la dinámica del palo y la zanahoria. Le Goff, J., La bolsa y la vida, Barcelona, Gedisa, 2013, p. 98.

15 "Satanás no tiene en la alta Edad Media un papel de primer plano, y aún menos el papel de una personalidad acusada. Aparece con nuestra Edad Media y se consolida en el siglo XI. Es una creación de la sociedad feudal". Le Goff, J., La civilización del Occidente medieval, Barcelona, Paidós, 2008, p. 138.

16 No obstante, la sospecha de la existencia soterrada de lo diabólico se extendía hasta cualquier hombre, en base a una concepción de su naturaleza como tendente al pecado. Cfr. Delumeau, J., Le peche et la peur, la culpabilisation en Occident, París, 1983.

17 "Era preciso sacar de la guarida al Anticristo, esto es, al Diablo, y aniquilarlo para que no pusiera en peligro la necesaria obra de expiación purificadora. El hombre cristiano se hizo cada vez más un individuo penitente. La introducción de la confesión personal y secreta en el cuarto concilio lateranense (1215) fue uno de los resultados de esta tendencia." Carozzi, C., Visiones apocalípticas en la Edad Media. El fin del mundo y la salvación del alma, Siglo XXI, Madrid, 2000, p. 100. 
depravante y contagiosa ${ }^{18}$. No obstante, analíticamente lo que constituyó el criterio para la acusación de herejía fue especialmente la obstinación en el error y la renuncia a aceptar la invitación de la Iglesia a regresar a su seno -u obediencia-. De suerte que el problema de la herejía no residía meramente en la desviación, sino también en la renuncia facultativa o rechazo a la retractación. Ello lo ilustra el hecho de que muchas prácticas de notable índole pagana que prevalecían en estos momentos en la Cristiandad no fueron consideradas heréticas ni condenadas criminalmente; más bien fueron objeto de catequesis y predicación ejemplarizante. Dicho metafóricamente, la herética pravedad no era una oveja descarriada, sino una zorra insidiosa y depravada ${ }^{19}$. A lo largo del siglo XII, líderes carismáticos como Roberto de Abrissel o Pedro de Bruys fueron tachados de herejes como los grupos de religiosos de Monteforte u Orleans, porque escogían una vida de pobreza evangélica no ortodoxa y se disponían a la predicación ejemplarizante de las enseñanzas de Cristo.

Además de renegada, la herejía era figurada también como contagiosa y camuflada. En continuidad con la tradición discursiva cristiana, se le atribuía un carácter sectario y secreto, vinculado a actividades clandestinas orgiásticas, sodomitas, infanticidas o abortivas ${ }^{20}$. Sin embargo, desde un punto de vista sociológico, el carácter oculto de la herejía durante el siglo XII se traduce en que, en última instancia, se trataba de una creencia heterodoxa potencialmente "oculta" en lo recóndito del alma o, incluso si se expresaba materialmente en una ortopraxis alternativa, en el secreto custodiado clandestinamente por la aquiescencia comunitaria. En tal sentido, el carácter oculto se constituía en relación al campo de visión de la Iglesia romana, era el reverso de los límites eclesiásticos -discursivos y materiales- para acceder a los pliegues del alma y a la complicidad comunitaria. Si bien el cristianismo había limitado el juicio eclesiástico del pecado oculto - pues solo la divinidad podía conocerlo-, a ello se añade que la ocultación herética surge también de las limitaciones institucionales del gobierno clerical para conocer, vigilar y exigir a las comunidades su obediencia.

Pese a la reforma de la administración romana, la Iglesia en el siglo XII todavía no estaba en condiciones de normalizar y reprimir con éxito el comportamiento laico y clerical. En tal sentido, en esta dinámica entre la extensión de la visión eclesiástica y la capacidad esquiva de la herejía, se desarrollarán dispositivos pastorales y jurídicos destinados a combatirla. La intelección escatológica de la existencia de obstáculos diabólicos para la salvación colectiva justificaba este despliegue efectivo de dispositivos, tanto pastorales como judiciales, inauditos en el sacerdocio espiritual cristianos ${ }^{21}$. Erradicar la herejía se presentaba como una condición para la salvación. La evolución de la política anti-herética del papado implicó así la emergencia de técnicas de identificación y corrección de la desviación. Si la herejía se perseguía una vez se registrada su obstinación al desacato de la ortodoxia y la ortopraxis romana, antes habría que descubrirla y desvelarla.

18 Fossier, A., "La contagion des péchés (XIe -XIIIe siècle). Aux origines canoniques du biopouvoir", en Tráces . Reveu de Sciences humaines, 21, 2, 2011, pp. 23-39.

19 Waugh, S. L., y Diehl, P. D., (ed) Christendom and Its Discontents: Exclusion, Persecution, and Rebellion, 1000-1500, Cambridge, Cambridge University press, 2002, p. 1.

20 Lambert, M., Medieval Heresy, op. cit. p. 3.

21 Por ejemplo, la cruzada fue empleada progresivamente en tanto que metáfora de la vida individual del cristiano como peregrinación penitente. Rivera, A., "La secularización después de Blumenberg", en Res publica, 11-12, pp. 95-142, 2003, p. 106. 


\section{Un cruce en el gobierno de las almas. Confesión y penitencia}

Será en este contexto del siglo XII cuando la confesión auricular se introduzca en el sacramento de la penitencia. Hasta entonces, la historia de la penitencia y la de la confesión en el cristianismo esbozan senderos diferentes. El cruce entre ambos dispositivos situaba la práctica del conocimiento de sí en el centro de la expiación que imponía la conducción pastoral de almas. Este encuentro -"el momento en que la tarea de decir la verdad sobre sí mismo se inscribe en el procedimiento indispensable de la salvación"- es interpretado por Foucault como un acontecimiento disruptivo en las modalidades históricas de subjetivación ${ }^{22}$. La confesión sacramental inauguraría así una forma de constitución del sujeto, de ética y de subjetivación muy distintos a la práctica de sí clásica ${ }^{23}$. Esta nueva hermenéutica de sí cristiana es relevante genealógicamente porque condensa las características de las relaciones y los modos de individuación propiamente pastorales que, en la modernidad, habrían de desplegarse en una multiplicidad de saberes-poderes gubernamentales, tales como las ciencias sociales o las prácticas de obtención de pruebas de verdad en los procedimientos judiciales ${ }^{24}$. La tecnología del yo confesional cristiana presuponía la existencia de una profundidad del alma que, mientras estaba velada su cognición inmediata, era susceptible de ser explorada por el propio sujeto. Pero, la exploración requería de la guía del pastor. Así, la verdad del yo se constituía como un objeto a descubrir y a revelar gracias a una introspección conducida por un otro facultado. En este sentido, la vigilancia constante sobre las voliciones propias, la relación entre el sujeto y su verdad en la confesión sacramental, estaba atravesada al mismo tiempo por la relación con la autoridad pastoral25.

Subrayar aquí el papel del guía eclesiástico-pastoral tiene como objeto señalar la relación entre el proceso de juridización sacramental y la nueva forma del dispositivo de la confesión penitencial. Por una parte, la inserción de la confesión en las prácticas penitenciales a partir del siglo XII implicará un acercamiento mimético del rol del confesor al del juez, sentando las bases para la conformación de un tribunal de la conciencia sobre almas-cuerpos. Por otra, la integración del testimonio confeso como prueba de verdad en un proceso judicial sitúa genealógicamente el dispositivo de la confesión en la constitución de los regímenes de veridicción y juridicción modernos -además de en la genealogía de los modos de subjetivación-.

Hasta que la confesión se vinculó al sacramento de la penitencia durante los siglos XII y XIII, la expiación tenía otros sentido en el cristianismo. La práctica penitencial antes del siglo VI consistía en un acto de reconocimiento público de ser un pecador -exomológesis-. En esta ceremonia, ordinariamente oficiada por el obispo, los pecadores ingresaban protocolaria y abiertamente en el estado de penitentes, sometiéndose a la ignominia y la vergüenza de la comunidad. Este rito colectivo reservado a pecados criminales, graves y notorios no

22 Castro, E., El vocabulario de Michel Foucault, Universidad Nacional de Quilmes, Quilmes, 2005, p. 90.

23 Foucault, M., Obrar mal, decir la verdad. La función de la confesión en la justicia, Madrid, Siglo XXI, 2014, p. 28.

24 Castro, R., Foucault y el cuidado de la libertad, Lom, Santiago de Chile, 2008, p. 280.

25 "Para el cristianismo habría un primer nivel de relación con la verdad: el acto de fe y de sometimiento a la autoridad de una institución con potestad sobre dicha verdad. Luego podría considerarse un segundo nivel de relación que representa un tipo de obligación distinto con la verdad, ya que involucra el ámbito de la relación del individuo consigo mismo". Ibid., p. 281. 
requería ni de la expresión verbal los pecados, ni del análisis introspectivo. Por el contrario, la remisión de las faltas era efecto de una experiencia sacrificial extensa en el tiempo. Así se purgaría el alma, siguiendo unas pautas de vida austera y flagelante. Ni la introspección analítica, ni la verbalización del pecado, ni la experiencia de contrición o arrepentimiento eran imperativos para lograr la purgación. Son estas últimas prácticas, que se introducirán posteriormente en la penitencia de la mano de la confesión auricular, las que presupondrán la existencia de la verdad interior velada y la conciencia de culpa ${ }^{26}$.

Cuando confesión y penitencia se cruzan en el nuevo sacramento, ambas cambian sustancialmente ${ }^{27}$. El paso de la penitencia solemne a la confesión auricular tuvo lugar por influencia de la penitencia tarifada practicada por los monjes irlandeses. Su analogía con la justicia germánica anticipaba ya el carácter judicializante que adquirirá la confesión, pues la penitencia tarifada instituía un sistema proporcional entre la falta cometida y la satisfacción requerida para la remisión de $\operatorname{los}$ pecados $^{28}$. En estos inicios, la verbalización del pecado ante el pastor no significa ipso facto la expiación del pecado, era aún un medio para ganarse la absolución mediante el cumplimiento de la penitencia impuesta. El propio acto de confesión al cura deviene en sí expiatorio al mismo tiempo que se dota a la revelación de los pecados de un carácter humillante ${ }^{29}$. La expiación del pecado pasaba entonces a ser efecto de la sentencia clerical de absolución. Ello indica que, al mismo tiempo que se hacía más imperativa la introspección y la renuncia de sí -actuando aquí el recogimiento interior-, incrementaba el papel exterior del director de la conciencia -y el imperativo de obediencia eclesiástica-. Si confesar el pecado implicaba desvelarse a sí mismo, también suponía la renuncia al yo. El potencial pecaminoso requería de un guía para el dominio de sí y de un corrector para la mala voluntad. De forma que el sacerdote conquistaba la potestad de expiar la culpa con una expresión que se asemejaría a un sentencia judicial, que decidía la pena absolutoria sin que fuese necesario que el pecador pasase primero por el largo camino de penitencia. Desde el siglo XII, el cura de almas evolucionará emulando la acción del juez, desarrollando técnicas para guiar al pecador en la identificación y revelación de su voluntad malévola. Éstas constituirán un nuevo arte del interrogatorio minucioso y persuasivo.

El hecho de que en el siglo XIII deviniese obligatoria este tipo de confesión significaba que la dirección de conciencia -y la hermenéutica de sí- dejaba de estar relegada únicamente a la vida cenobítica para extenderse también al laicado ${ }^{30}$. El IV Concilio de Letrán instituía entonces la confesión al párroco propio como una práctica sacramental obligatoria, anual y periódica $^{31}$. La extensión de esta práctica penitencial estaba atravesada por numerosas tensiones, pues convivían al mismo tiempo demandas de nuevas formas de dirección espiritual

26 Foucault, M., Obrar mal, decir la verdad., op. cit., p. 187.

27 Castro, R., Foucault y el cuidado de la libertad, op. cit., pp. 290-291.

28 Chiffoleau, J., La chiesa, il segreto e l'obbedienza. Il Mulino, Milán, 2010, p. 27.

29 Castro, R., Foucault y el cuidado de la libertad, op. cit., pp.292-293.

30 Se podría decir se trataba de un proceso lento de monaquización que afectaría a toda la sociedad cristiana. El modelo de pureza de hábitos o de vida ascético-monástico se extendió primero al clero secular -desde el regular- para finalmente imponerse también como ideal de conducta al laicado.

31 El individuo debía revelar al sacerdote todas y cada una de las faltas -pecados graves y veniales-cometidas desde la última vez cada año todos los años de su vida. 
con una diversidad de resistencias a la imposición eclesiástica de los nuevos cultos sacramentales. En los manuales de confesión y penitenciales de la época, las artes propuestas para desvelar pecados ocultos -mediante la implicación activa del sacerdote- dejan entrever las fuertes resistencias de los fieles a confesarse, esto es, a convertirse en culpables confesos. Su sentido reside precisamente en que la confesión estaba muy lejos de ser un acto espontáneo. Se hacía necesario por ello recurrir a todo tipo de formas para descubrir, desvelar y visibilizar lo pecaminoso, a técnicas de persuasión para sonsacar pecados o guías metódicas para ayudar a la auto-investigación del pecador. No obstante, si el dispositivo de la confesión hubiese tenido éxito, su efecto habría sido la ampliación del espectro de los pecados que la Iglesia podría conocer a través de los interrogatorios y de la persuasión confesional del cura ${ }^{32}$.

Este tipo de confesión penitencial se insertaba en una concepción de la justicia eclesiástica fruto de la apropiación proyectiva por la Iglesia de los caracteres de la justicia divina omnisciencia y omnipotencia- ${ }^{33}$. Ello se traduce efectivamente en el proceso de juridización de la pastoral -de los servicios sacramentales de cura de almas-. La forma gubernativa de esta Iglesia medieval es dual, combina formas de ejercicio del poder pastorales y jurídicas que presuponen que la voluntad de los cuerpos-almas ha ser convergente con la norma eclesiástica. El sacramento de la penitencia por confesión se convirtió, en este marco, en un nodo donde confluían la justicia de Dios y la de la Iglesia, donde se cruzaban lo intangible y lo tangible. Esta intersección tendía a la convergencia del derecho divino y del eclesiástico, desafiando con ello el límite del gobierno pastoral para juzgar los secretos del alma. Este límite estaba vinculado al principio tradicional del cristianismo que convenía que la Iglesia no podría juzgar lo oculto - ecclesia de occultis non iudicat ${ }^{34}$. En tal sentido, la práctica guiada de la hermenéutica de sí, que guiaba al sujeto a un conocimiento de sí purgativo mediante la negación de la voluntad propia, también hubo de permitir al gobierno pastoral el desvelamiento de voluntades obstinadas en el error, de sujetos rebeldes y soberbios. La dualidad del pastorado medieval se manifiesta aquí en que cuando la producción de un sujeto dócil y humilde no fue exitosa -en términos de una interioridad constituida como subjetividad facultativamente sometida- el juicio de las alma implicaba una corrección de cuerpos que llegó hasta el suplicio o la aniquilación.

\section{Condenar los cuerpos de las almas rebeldes. Inquisición y delación}

Una vez establecida la obediencia a la Iglesia como única vía hacia la salvación, los pecados graves de inobediencia al pastorado romano pasaron a ser percibidos como un peligro para el cuerpo eclesiástico en su totalidad. En tanto que la Iglesia reclamaba el monopolio sobre la ortopraxis y la ortodoxia, la desviación herética era considerada un desafío al aval de salvación romano. La divinización del oficio pastoral hacía de la desobediencia obstinada a Roma un agravio al papel de la Iglesia en el plan de salvación divino, lo que justificó que la

32 Prodi, P., Una storia della giustizia, Il Mulino, Milán, 2000, p. 74.

33 "Sea como fuere; la Iglesia se convirtió (...) en la institución dentro [de la] cual se juridizan fundamentalmente las relaciones entre Dios y el hombre. A partir de allí comienza o se desarrolla el gran olvido de San Agustín; a partir de allí también comienza toda una serie de efectos y consecuencias que serán precisamente las cosas contra las cuales se levantará la Reforma.” Foucault, M., Obrar mal, decir la verdad., op. cit., p. 204.

34 García y García, A. (ed.) Constitutiones Concilii quarti Lateranensis, op. cit., c.39. 
herejía fuera finalmente caracterizada como un crimen de traición contra la autoridad divina. Juzgar el pecado herético como crimen en el foro externo o las infracciones clericales en el foro interno fue percibido como una defensa de la propia institución eclesiástica, cuya subsistencia se consideraba imprescindible para el cumplimiento del plan de salvación divino.

$\mathrm{Si}$ en principio el juicio eclesiástico estaba circunscrito a los pecados notorios o a los confesos, el desarrollo combinado de técnicas penitenciales y coactivas amplió notablemente su alcance ${ }^{35}$. La extensión de la capacidad eclesiástica de conocer, cauterizar y sancionar conductas desviadas de la ortodoxia/ortopraxis tuvo lugar gracias a los nuevos procedimientos de la denuncia canónica y de inquisición, así como a la inserción de la confesión como testimonio de inculpación. Con ello se hacía posible el traslado de los pecados de la esfera de lo secreto u oculto a la de lo notorio o evidente, y su consecuente juico como crímenes. La racionalización jurídica y teológica de los modos en que el pecado podía manifestarse -hacerse manifiesto- se desarrolla en paralelo a las nuevas nociones en torno a lo notorio -manifestum- y lo oculto -ocultum-, que transformaban los presupuestos cognoscitivos del altomedioevo. En el marco de la persecución de la herejía, ciertos pecados hasta entonces restringidos a la corrección sacramental pasaron a ser juzgados como crímenes en los tribunales eclesiásticos ${ }^{36}$; mientras que el juicio del delito notorio de la simonía clerical fue trasladado al ámbito penitencial para no alentar el escándalo -en su sentido medieval, como seducción a la imitación del pecado- ${ }^{37}$. Lo que significa que los dispositivos de la inquisición y la confesión se desarrollaban en una relación dinámica con las resistencias a las distintas formas de juicio eclesiástico.

El proceso por inquisición se fue conformando ante las restricciones que las formas de juicio eclesiástico implicaban a la hora de perseguir y juzgar los pecados graves del propio clero. Durante la llamada reforma gregoriana, cuando prosperaban los juicios a clérigos acusados de simonía y de prácticas sexuales contra natura ${ }^{38}$, los procedimientos vigentes en la Iglesia para juzgar los pecados manifiestos del clero eran el proceso de sumario o los juicios de Dios - donde las pruebas contra el acusado se obtenían a través de la ordalía o el juramento-, mientras que para los crímenes secretos, el derecho canónico ofrecía los procesos de acusación y denuncia. Por su parte, la acusación hacía a la Iglesia dependiente del testimonio de un acusador para poder perseguir el crimen de simonía o las conductas sexuales desviadas. Debido a que dichos pecados podían ser secretos, el proceso por acusación resultaba insuficiente para perseguir la indisciplina clerical. Igualmente, las ordalías resultaron también contraproducentes para la Iglesia en la tarea de disciplinar al

35 Chiffoleau, J., La chiesa, il segreto e l'obbedienza, op. cit., p. 83.

36 Ibid.p. 75.

37 Que un pecado clerical se hiciera público suponía una amenaza porque ofrecía un contra-ejemplo de una conducta susceptible de ser emulada por otros. Escandalizar no significaba provocar un estado de indignación, sino crear la ocasión de que otro cometiese un pecado similar al ser seducido por la imaginación. La publicidad de las prácticas de simonía o fornicación clerical aparecen en la literatura doctrinal como tentadores modelos de conducta. El peligro de escándalo que suponía juzgar los crímenes clericales en el foro externo por hacerlos notorios fue la justificación que esgrimieron los canonistas para castigarlo penitencialmente, en secreto. Fossier, A., "La contagion des péchés (XIe -XIIIe siècle). Aux origines canoniques du biopouvoir", en Tráces. Reveu de Sciences humaines, 21, 2, pp. 23-39, 2011, pp. 29-30.

38 Cfr. Chiffoleau, J., "Contra Naturam: pour une approche casuistique et procédurale de la nature médiévale”, en Micrologus: Natura, scienze e società médiévale, 4, 1996, pp. 265-312. 
clero debido a que el fallo sobre el acusado dependía del criterio de las comunidades o del de la jerarquía local -además de que eran inviables si no existía acusación previa o testigos- ${ }^{39}$. Si bien el recurso a la delación popular de los delitos clericales podía ser eficaz porque la comunidad podía advertirlos por su cercanía, no dejaba de ocasionar problemas al gobierno romano porque no estaba en condiciones de controlar el sentido -o la veracidad- de la acusación y la sentencia. Los motivos de acusación eran múltiples y no siempre fáciles de probar: ser hijos de prostitutas o hijos bastardos, leprosos, siervos, simoníacos, trúhanes o villanos, herejes, blasfemos, sacrílegos o disponer de concubinas ${ }^{40}$. Las dificultades romanas para controlar los veredictos locales en los juicios de Dios influyó en la decisión de prohibir las ordalías y los juramentos en la justicia eclesiástica ${ }^{41}$, a partir del IV Concilio de Letrán ${ }^{42}$.

En este contexto emergían los procedimientos judiciales por investigación y por denuncia canónica ${ }^{43}$. Aunque su desarrollo definitivo tuvo lugar en el contexto de la lucha contra la herejía a principios del siglo XIII, unas décadas antes se justificaba ya su empleo en la persecución de los excesos clericales gracias a una operación que permitía ampliar la evidencia de lo manifiesto ${ }^{44}$. En tanto que la calificación de un crimen como notoruim o manifestum no hacía imprescindible la existencia de una acusación previa para que un juez aplicase un castigo al criminal, el nuevo proceso judicial consistía en iniciar una indagación a partir de la sospecha de un pecado criminal. El rumor deviene entonces un indicio judicial. La canonística instituía la posibilidad de conocer lo oculto mediante los indicios ex evidentia o ex fama en la decretal Licet Heli (1199) emitida por Inocencio III contra la simonía ${ }^{45}$. Durante este pontificado el procedimiento se legalizó y se expandió instituyéndose como procedimiento judicial en el decreto Qualiter et quomodo-octavodel IV Concilio Lateranense, donde la fama se introducía como una forma de denuncia, razón suficiente para proceder a una investigación ${ }^{46}$.

39 En los siglos XI y XII las ordalías se emplearon en muchos casos como pruebas acusatorias contra el centralismo del partido reformista y a favor de la política local.

40 Moore, I. R., La guerra contra la herejía, Crítica, Barcelona, 2014, p. 80.; Gaudemet, J., Église et cité, op. cit., pp. 91-92.

41 Pennington, K., "Torture and Fear: Enemies of Justice”, en Rivista internazionale di diritto comune, 19, 2008, pp. 203-242, 2008, p. 12.

42 En el canon 18 del IV concilio de Letrán, Sententiam Sanguini. García y García, A. (ed.) Constitutiones Concilii quarti Lateranensis, op. cit., c. 18.

43 La denuncia canónica se desarrolló a partir de la fórmula de la denunciatio evangelica propia de la esfera sacramental modelada sobre el principio de la corrección fraterna. Chiffoleau, J., La chiesa, il segreto e l'obbedienza, op. cit., p. 79.

44 Ibid., p. 69.

45 Ibid., pp. 91-95.

46 Inocencio III no había modificado sustancialmente la forma de la inquisición episcopal introducida ya en la bula Ad Abolendam decretada por el papa Lucio III en 1184. Jiménez, P., "La inquisición contra los Albigenses en Languedoc (1229-1329)", en Clío y Crimen, 2, pp. 53-80, 2005, p. 61. Según la bula Ad Abolendam, aquellos de quienes se tuviera sospecha notoria habían de ser sometidos al juicio del obispo. La bula permitía que, según el tipo de sospecha y la cualidad de la persona, el hereje pudiera resarcir su error. Sin embargo, si la sospecha notoria recae sobre un reincidente, entonces habría que enviarlo al brazo secular para que fuese castigado -probablemente con la hoguera- sin posibilidad de apelación. 
El desarrollo ulterior de la inquisición y la confesión en los procedimientos judiciales eclesiásticos estuvo vinculado a la dinámica de persecución de la herejía ${ }^{47}$.Si bien en un principio la herejía era un creencia errónea y habría de ser juzgada en los occulta cordis del foro interno, la categoría intelectiva de lo semi-oculto, junto con el testimonio confeso y la indagación por indicio, posibilitaron la revelación de los pecados ocultos para ser juzgados judicialmente ${ }^{48}$. En paralelo, la herejía era tipificada como un crimen de traición a partir de la bula Vergentis in senium, sirviéndose de las categorías del derecho romano imperial ${ }^{49}$. Los herejes era representados como un peligro para la comunidad eclesial por el carácter contagioso y clandestino - occultatio diavolica - de su heterodoxia, que sostenían de manera pertinaz $^{50}$. De modo que la herejía podría esconderse tanto en los secretos del alma como en las prácticas clandestinas bajo el amparo comunitario.

En este marco se extendía la actuación activa de la Iglesia para desvelar lo oculto ante la sospechaba de una amenaza pública. Un oficial eclesiástico podía iniciar la búsqueda de pruebas tomando la fama como indicio de un crimen, sin necesidad de que un acusador privado iniciase un recurso. En este sentido, lo semi-oculto expresaba un movimiento del saber, un tránsito de la razón de lo oculto a lo manifiesto, gracias a la ficción jurídica del notorium iuris que categorizaba el potencial desvelamiento de un pecado cuando existían indicios que pudiesen servir como pruebas judiciales. Lo que fue acompañado de nuevos modos de racionalizar la cognición de hechos fácticos, la veracidad de las pruebas judiciales como evidencia de hechos y su relación con las cualidades de los indicios de culpabilidad ${ }^{51}$. Se trataba de una nueva percepción de la dinámica entre lo notorio y lo secreto que, al enfrentarse intelectiva y procesualmente con la evidencia y el indicio del hecho, fabricaba nuevas concepciones de la verdad y del acceso cognoscitivo a la misma. La verdad en el juicio de la herejía emergía de la reconstrucción ficticia pero verisímil de un hecho mediante la presentación de pruebas que lo hiciesen "racionalmente" evidente, a diferencia de los juicios de Dios. La verdad criminal resultaba, en principio, de la posibilidad de ser probada mediante procesos de verificación, demostración y comprobación respecto a un hecho reconstruido ficticiamente. Frente a ello, en la época altomedieval eran el testimonio y la fe las formas de evidencia o certeza de lo acontecido - no sólo en el juicio, también en la cronística por ejemplo-; el criterio de verdad lo constituía la honorabilidad del sujeto que testimoniaba y enunciaba lo acontecido ${ }^{52}$. Pero, a partir de la emergencia de los procedimientos de denuncia canónica e inquisición, y su combinación con la confesión auricular, el testimonio pasaba a ser una prueba más de verdad, susceptible de ser contrastada con otras evidencias no siempre atestadas ${ }^{53}$.

47 Pennington, K., "Torture and fear", op. cit., pp. 212-213.

48 Chiffoleau, J., La chiesa, il segreto e l'obbedienza, op. cit., p 71.

49 Fossier, A., "La contagion des péchés", op. cit., p. 32.

50 Chiffoleau, J., La chiesa, il segreto e l'obbedienza, op. cit., p. 137.

51 Moore, I. R., La guerra contra la herejía, op. cit., p. 133.

52 Pomian, K., Sobre la historia, Madrid, Cátedra, 2007, pp. 64-65.

53 Fraser considera que la abolición de las ordalías es un efecto del proyecto de Inocencio III de controlar jerárquicamente el proceso criminal e incrementar la eficiencia eclesiástica en la incriminación e imputación criminal. R. Barlett considera que en dicha abolición confluyeron los intereses de los canonistas, la curia papal y los partidarios de la reforma eclesiástica. Fraser, R. M., "IV Lateran's Revolution in criminal procedure" en Studia 
Este tipo de verdad judicial es indisociable de la sistematización y calificación jurídica de los pecados graves ${ }^{54}$. El hecho criminal herético existía por su previa tipificación jurídica como crimen. Si el juicio eclesiástico sancionaba la inobediencia a su norma según su propia tipificación, ello significaba que la justicia eclesiástica no se dedicaba ya solamente a hacer de árbitro en una acusación de agravio y/o a sancionar una indisciplina escandalosa. En esta línea, Inocencio III categorizó jurídicamente conductas sociales que auxiliaban a o condescendían con la vida herética. El proceso por inquisición en regiones donde la herejía estaba extendida dependía demasiado de la confesión acusatoria o del testimonio inculpatorio. Ante ello, la bula Vergentis in senium ofrecía herramientas a los obispos para extender los castigos a las comunidades. Ahora el episcopado podría identificar a celatores, receptatores u ocultatores e imponerles penas de excomunión, privarlos de derechos, confiscar sus bienes y privar de herencia a sus hijos ${ }^{55}$. Unos castigos que imitaban a los empleados por el antiguo derecho romano, cuando la pena del culpable se transmitía a su descendencia. Esta estrategia, además de ampliar el radio de incriminación, quebraba los vínculos de solidaridad de las comunidades fomentado la desconfianza al introducir figuras como la del confidente, el delator o el acusador.

La bula Vergentis in senium fue distribuida en una carta circular a prelados y príncipes fuera del Lacio, especialmente en las regiones del Languedoc y Provenza, donde tendría lugar la cruzada contra la herejía albigense (1209-1229). Las élites de estas regiones organizadas principalmente en condados y ducados autónomos -tanto señores laicos como eclesiásticos- de los poderes imperiales, regios y papales eran reacias al centralismo romano. Esto hacía más complicado el sometimiento al gobierno pontificio de estas élites señoriales y de las comunidades rurales y urbanas locales, donde se practicaban de forma extensa formas de religiosidad heterodoxas como las cátaras o valdenses. El amparo del conde de Toulouse Raimundo VI a las resistencias del clero local ante Roma y a la extensión de las contra-economías de salvación identificadas como heréticas profundizó el conflicto con los legados papales. Hasta el punto de que en 1208 este conde fue acusado como autor intelectual del asesinato del legado papal Pierre de Castelnau. Hecho que desencadenó la llamada de Inocencio III a la denominada Cruzada albigense, que se prolongó brutalmente durante los siguientes veinte años ${ }^{56}$. En este contexto de guerra interna contra la herejía se sitúan algunos de los desarrollos de los procedimientos judiciales y penales anteriormente expuestos.

No obstante, ni siquiera la brutal cruzada albigense significaría el final de la persecución de la herejía ${ }^{57}$. La inquisición papal y el empleo oficial de la tortura para sonsacar una confesión como prueba judicial se instituyeron en las décadas posteriores. Si en el Concilio lateranense de 1215 se sistematizaron los procedimientos de incriminación de la herejía, en

in honorem eminentissimi cardinalis Alphonsi M. Stickler, en Castillo R (ed.), Studia et textus historiae iuris canonici, vol. 7, Roma, Libreria Ateneo Salesiano, pp. 97-11, 1992, p. 99.

54 Lambert, M., Medieval Heresy, op. cit., p. 102.

55 Véase el epígrafe cuarto de la bula Bula Ad Abolendam.

56 Cfr. Laval, P., Los Cátaros. Herejía y crisis social, Barcelona, Crítica, 1988; Marvin, L., The Occitan War: A Military and Political History of the Albigensian Crusade, 1209-1218, Cambridge, Cambridge University Press, 2008; Pegg, M., A Most Holy War: The Albigensian Crusade and the Battle for Christendom, Oxford, Oxford University Press, 2008.

57 Barber, M., The Cathars: Dualist Heretics in Languedoc in the High Middle Ages, op. cit., p. 139 y ss. 
1230 - un año después del final de la Cruzada albigense-el papa Gregorio IX instituía el tribunal específico de la inquisición papal para perseguir la herética pravedad. Se establecía así un tribunal dependiente directa y exclusivamente de Roma, diferenciado de la inquisición como procedimiento judicial en los tribunales diocesanos ordinarios. Un organismo judicial con capacidad de intervención reticular, pero implementado ad hoc con independencia de las jurisdicciones locales o de los tribunales diocesanos. Estas inquisiciones papales, que podían prolongarse extensamente en el tiempo, estaban dotadas de amplios poderes y desarrollaron un saber hacer experto en la persecución de la herejía, dotándose de técnicas avezadas en la identificación y la inculpación. Los propios manuales para inquisidores fueron escritos recogiendo la experiencia de los frailes en los tribunales de dichas regiones, y sus descripciones y categorizaciones de la herejía sirvieron como herramienta para la polémica escolástica ${ }^{58}$.

Las artes inquisitoriales para la persecución herética penetraban en la vida de las comunidades deteriorando los vínculos de solidaridad previos ${ }^{59}$ y las formas organizativas locales ${ }^{60}$. La incitación a la delación en los interrogatorios y en ceremonias públicas mediante sermones que pretendían atemorizar a las comunidades generaban un clima de desconfianza. El miedo a los inquisidores podía proyectarse a los vecinos ante la sospecha de que fuese un confidente o un posible delator. Esta quiebra de la confianza y solidaridad comunitaria era fundamental en el contexto del Languedoc y la Provenza, donde las prácticas heterodoxas de cura de almas y la organización eclesial como las llamadas cátaras o valdenses se fundamentaban en vínculos de amistad, fidelidad y afinidad -en su sentido medieval-.

Pero, pese a la ferocidad de la persecución herética, las resistencias al gobierno pontificio y sus delegados no cesaban. En las ciudades italianas gibelinas, partidarias del Emperador, se intentaba boicotear la actuación de la inquisición. En la provincia eclesiástica de Narbona se desencadenaron disturbios contra los tribunales pontificios durante la década de 1230, en las ciudades de Toulouse y Albi. A finales del siglo XIII, en esa misma región se organizó un movimiento con el propósito de impedir la actuación inquisitorial en el que participaban representantes de las ciudades de Carcasona, Albi, Castres, Cordes y Limoux, liderado por el franciscano Bernard Délicieux. Ante estas resistencias, a mediados del siglo XIII, Inocencio IV dio un paso más en la persecución de la herejía autorizando el empleo de la tortura para obtener una confesión como testimonio inculpatorio ${ }^{61}$. Aunque de facto ya se recurría frecuentemente a ella, en 1252 se dio licencia oficial para que se tomase como prueba de verdad el testimonio obtenido bajo tortura ${ }^{62}$. A través del suplicio del cuerpo, se juzgaba el alma impenetrable. La confesión forzada deviene así una prueba de verdad inculpatoria. Todo indica que, si la enunciación provocada tortuosamente era tomada como certeza, la tortura hacía simplemente evidente una verdad de un alma-cuerpo ya condenado. Este fenó-

58 Thery, J., «Les hérésies, du XIIe au debut du XIV siècle», en Marie-Madeleine de Cevins; Jean Michel Matz (eds.), Structures et dynamiques de la vie religieuse en Occident (1179-1449), Presses Universitaires de Rennes, Rennes, pp. 373-386, 2010, p. 382-383.

59 Given, J., "Social stress, social strain, and the inquisitors of Medieval Languedoc", en Waugh, S. L., y Diehl, P. D., (ed) Christendom and Its Discontents: Exclusion, Persecution, and Rebellion, 1000-1500, Cambridge, Cambridge University press, 2002, pp. 67-85, aquí pp. 68-69.

60 Cfr. Arnold, J., Inquisition and Power. Catharism and the Confesing Subject in Medieval Languedoc, Pennsylvania, University os Pennsylvania press, 2001.

61 Lambert, M., Medieval Heresy, op. cit., p. 103.

62 Pennington, K., "Torture and Fear: Enemies of Justice”, op. cit., pp. 203-242., aquí p. 216. 
meno manifestará la imposibilidad y la quiebra histórica del sueño autoritario pontificio, una soberanía perfecta, donde la prescripción gubernativa y la voluntad de los gobernados coincidiesen. La aspiración a la ortodoxia/heterodoxia de un gobierno pastoral juridizado hubo de pasar por la persecución y aniquilación de heterodoxos y rebeldes.

\section{Referencias}

ARNOLD, John H. (2001), Inquisition and Power. Catharism and the Confesing Subject in Medieval Languedoc, University of Pennsylvania Press, Pennsylvania.

BARBER, Malcolm (2014), The Cathars: Dualist Heretics in Languedoc in the High Middle Ages, Routledge, Londres / Nueva York.

BLUMENBERG, Hans (2008), La legitimación de la Edad Moderna, Pre-textos, Valencia.

CAROZZI, Claude (2000), Carozzi, C., Visiones apocalípticas en la Edad Media. El fin del mundo y la salvación del alma, Siglo XXI, Madrid.

CASTRO, Edgardo (2005), El vocabulario de Michel Foucault, Universidad Nacional de Quilmes, Quilmes.

CASTRO, Rodrigo (2008), Foucault y el cuidado de la libertad, Lom, Santiago de Chile.

CHIFFOLEAU, Jacques (1996), "Contra Naturam: pour une approche casuistique et procédurale de la nature médiévale", en Micrologus: Natura, scienze e società médiévale, 4, pp. 265-312.

CHIFFOLEAU, Jacques (2010), La chiesa, il segreto, l'obbedienza, Il Mulino, Milán.

DELUMEAU, Jean (1983), Le peche et la peur, la culpabilisation en Occident, Fayard, París.

FOSSIER, Arnaud (2011), "La contagion des péchés (XIe -XIIIe siècle). Aux origines canoniques du biopouvoir”, en Tráces. Reveu de Sciences humaines, 21, 2, pp. 23-39.

FOUCAULT, Michel (2014), Obrar mal, decir la verdad. La función de la confesión en la justicia, Madrid, Siglo XXI.

FRASER, Richard M. (1992), "IV Lateran's Revolution in criminal procedure. The birth of Inquisition, the end of ordeals, and Innocent III's vision of Ecclesiastical politics" en Studia in honorem eminentissimi cardinalis Alphonsi M. Stickler, en Castillo R (ed.), Studia et textus historiae iuris canonici, vol. 7, Roma, Libreria Ateneo Salesiano, pp. 97-111.

GARCÍA Y GARCÍA, Antonio (1981), Constitutiones Concilii quarti Lateranensis una cum Commentariis Glossatorum. Monumenta iuris canonici(ed.), Series A: Corpus Glossatorum, vol. 2, Città del Vaticano, Biblioteca apostolica vaticana, c.1 .

GAUDEMET, J. (1994), Église et cité: histoire du droit canonique, París, Cerf-Montchrestien.

GIVEN, James (2002), "Social stress, social strain, and the inquisitors of Medieval Languedoc", en Waugh, S. L., y Diehl, P. D., (ed) Christendom and Its Discontents: Exclusion, Persecution, and Rebellion, 1000-1500, Cambridge University press, Cambridge, pp. 67-85,

JIMÉNEZ, Pilar (2005), "La inquisición contra los Albigenses en Languedoc (1229-1329)", en Clío y Crimen, 2, pp. 53-80.

LAMBERT, Malcolm (2002), Medieval Heresy: Popular movements form the Gregorian Reform to the Reformation, Blackwell, Oxford and Malden. 
LAVAL, Paul (1988), Los Cátaros. Herejía y crisis social, Crítica, Barcelona.

LE GOFF, Jacques (1989): El Nacimiento del Purgatorio, Taurus, Madrid.

LE GOFF, Jacques (2008), La civilización del Occidente medieval, Barcelona, Paidós.

LE GOFF, Jacques (2013), La bolsa y la vida, Gedisa, Barcelona.

LOBRICHON, Guy (1994), La religion des laïcs en Occident: XIe-XVe siècles, Paris, Hachette.

MARVIN, Laurence (2008), The Occitan War: A Military and Political History of the Albigensian Crusade, Cambridge University Press, Cambridge.

MOORE, Robert Ian (2003), La primera revolución europea: c.970-1215, Crítica, Barcelona.

MOORE, Robert Ian (2014), La guerra contra la herejía, Crítica, Barcelona.

PEGG, Mark Gregory (2008), A Most Holy War: The Albigensian Crusade and the Battle for Christendom, Oxford University Press, Oxford.

PENNINGTON, Kenneth. (2008), “Torture and Fear: Enemies of Justice”, en Rivista internazionale di diritto comune, 19, 2008, pp. 203-242.

POMIAN, Krzysztof (2007), Sobre la historia, Cátedra, Madrid.

PRODI, Paolo (2000), Una storia della giustizia, Il Mulino, Milán.

RIVERA, Antonio (2003), "La secularización después de Blumenberg", en Res publica, 11-12, pp. 95-142.

RODRIGUEZ MOLINA, Jesús (2008), "La confesión auricular. Origen y desarrollo histórico", en Gazeta de Antropología, 24, 1.

THÉRY, Julien (2009), “Fama: la opinión pública como presunción legal. Apreciaciones sobre la revolución de lo inquisitorio (siglos XII-XIV), en E. Dell’Elicine, P. Miceli, y A. Morin (eds.) De Jure: Nuevas lecturas sobre derecho medieval, Ad-Hoc, Buenos Aires.

THÉRY, Julien (2010), "Les hérésies, du XIIe au debut du XIV siècle", en Marie-Madeleine de Cevins; Jean Michel Matz (eds.), Structures et dynamiques de la vie religieuse en Occident (1179-1449), Presses Universitaires de Rennes, Rennes, pp. 373-386.

THÉRY, Julien (2006), «Innocent III, le rêve de la théocratie” en Les collections de L'Histoire, 26, pp. 58-61.

VIOLANTE, Cinzio (1955), La pataria milanesa e la riforma ecclesiastica, Instituto storico italiano per il Medioevo, Roma, 1955.

WAUGH, Scott L., y DIEHL, Peter D., (eds.) (2002) Christendom and Its Discontents: Exclusion, Persecution, and Rebellion, 1000-1500, Cambridge University Press, Cambridge.

WEBER, Max (1978), Sociología de la religión, Buenos aires, La pléyade. 